\title{
A EDUCAÇÃo FísICA INFANTIL NAS ESCOLAS DE HABILITAÇÃO DE MAGISTÉRIO NAS escolas PUblicas de são paulo
}

\author{
Ana Cristina ARANTES*
}

\begin{abstract}
A exposição preparada para este Seminário de Educação Física tem por objetivo fundamental tornar conhecida a realidade da disciplina Educação Física Infantil ministrada na habilitação especifica de 20. grau para o magistério nas escolas públicas da cidade de São Paulo.

Convém ressaltar que este componente curricular por força de Del.30/87 é mais oferecido oficialmente nas escolas públicas em São Paulo. Assim sendo, as aulas destinadas ao conhecimento e metodologia desta área tem sido ministradas tão somente com o caráter de atividade.

$O$ interesse em pesquisar a situação da Educação Física Infantil (Arantes, 1990) esteve diretamente ligado à formação acadêmica do investigador. Normalista, licenciado em Educação Física e em Pedagogia reúne conhecimentos acerca da habilitação em tela tanto na qualidade de aluno quanto na condição de docente uma vez que ministrou este componente em escola de iniciativa privada em São Paulo. Além deste fato, por inúmeras vezes atuou como professor responsável nos cursos de atualização e reciclagem oferecidos aos professores polivalentes e especialistas pertencentes a rede estadual de ensino.
\end{abstract}

\section{CONSIDERAÇÕES HISTÓRICAS}

A habilitação especifica de 2o. grau para o magistério mais conhecido como Curso Normal, teve sempre por objetivo primordial oferecer capacitação profissional para a docência nos quatro primeiros anos de escolaridade.

Praticamente desde a sua criação, em 1846, antes mesmo da existência do secundário, o Curso de Formação de Professores Primários jamais recebeu a devida atenção (Fusari \& Cortese, 1989). Sobrevivendo às transformações sociais e às inúmeras reformas de ensino $(1920,1927,1946,1961,1968 \mathrm{e}$ a de 1971 como afirma Lelis, 1989), esta habilitação de caráter profissionalizante acompanhou a descaracterização do ensino - situação esta resultante dentre as inúmeras razões pela inadequada e crescente desvalorização dos cursos de 30. grau e a insuficiente e desarticulada política educacional fatores estes que incidiram diretamente na qualidade do ensino de 10. grau.

Inicialmente idealizado para ambos os sexos, foi sendo progressivamente ocupado por moças da classe abastada cujo objetivo era o de prosseguir nos estudos ou ampliar sua cultura geral antes do casamento. Este fato foi modificado pela Lei 5692/71, quando um número maior de pessoas tiveram acesso à escolarização inclusive aquelas economicamente desfavorecidas.

Importante salientar, que ser professora até a década de 30 representou para a sociedade brasileira a única profissão respeitável e uma forma institucionalizada de empregar pessoas do sexo feminino (Campos, 1987).

\footnotetext{
*Escola de Educação Física da Universidade de São Paulo.
} 
Com relação à Educação Física Infantil, presente em quase todos os currículos desde o Império, adotou segundo as concepções filosóficas, várias denominações: Recreação e Jogos, Educação Física, Ginástica (Piletti, 1987).

Inserida na grade curricular das Escolas Normais sempre refletiu o pensamento da política educacional vigente. Por vezes obrigatória, quase sempre esteve vinculada ao regime político existente na confecção dos programas. Adotou postura de adestramento físico objetivando saáde e a eugenia da raça, em outra ocasião seu conteúdo foi constituído pelo desenvolvimento das habilidades de convivio social (Cantarino Filho, 1982; Medalha, 1985).

Foi ao longo de sua trajetória, concebida ora como cadelra, prática educativa, atividade ou como disciplina pertinente ao quadro de formação especifica. Foi em seus primórdios lecionada por leigos posteriormente, passou a apresentar uma fisionomia diferenciada talvez pela contratação de professores formados nas Escolas Superiores de Educação Física em 1931-1935 aproximadamente como explicita Corpo e Movimento (1984).

Idealizada pelos estudiosos deveria possibilitar a futura professora o contacto, conhecimento e a aplicação de inúmeros conceitos inerentes ao processo de crescimento e desenvolvimento infantil, legislação, preparação e implementação de planos de ensino (CENP, 1979). No entanto, o que se observou é que esta disciplina até 1989 não recebeu o tratamento necessário e adequado.

Para que se chegasse a esta conclusão, o investigador aplicou um questionário em 17 professores especialistas e em seus 226 estudantes da última série do curso. A realidade encontrada coincidiu com os dados levantados pelos estudos semelhantes elaborados por outros pesquisadores em diferentes épocas (Piconez, 1988; Sasaki, 1988 dentre outros).

Além deste instrumento, o autor deste trabalho, entrevistou os discentes e professores responsáveis pela disciplina que somadas a minuciosa análise comparada dos planos de ensino e o documento oferecido pela CENP (1979), ofereceram subsídios suficientes para os resultados que se seguem.

\section{RESULTADOS DE PESQUISA}

Através do estudo, pode o investigador concluir que a grande maioria dos alunos é do sexo feminino; são jovens solteiras pertencentes à classe social média. Afirmaram em seus questionários que escolheram cursar esta habilitação por razões vocacionais e que além do curso regular, já freqüentaram muitos outros cursos de rápida duração tais como datilografia, cabeleireira, auxiliar de escritório e computação.

Mais da metade embora tivesse intenção de cursar o 3o. grau, naquele momento não reuniam condições para freqüentar uma faculdade concomitantemente.

Os respondentes afirmaram que apesar de conviver com graves problemas que fatalmente recaem sobre sua formação, sentiam-se satisfeitos com aquilo que lhes fora ministrado. Talvez esta percepção inadequada, esteja diretamente ligada ao fato de que cabe ao professor formado em nível superior a responsabilidade de ministrar as aulas de Educação Física para os alunos de pré-escola e 1a. a 4a. série do 1o. grau.

Observou-se também que este aluno de 20. grau tem escolaridade superior a de seus pais e o diploma de duvidosa qualidade, representa para este estudante, algo significativo para quem atua nas escolas como auxiliar ou regente sem mesmo ter completado sua formação profissional.

Com relação ao professor especialista, a grande maioria à semelhança dos seus alunos é do sexo feminino com idade concentrada entre 20-25 anos de idade. Tem em mais da metade da amostra, pouca experiência no magistério e sua formação acadêmica é proveniente de instituições superiores particulares. 
Apesar de terem escolhido a profissão por vocação e satisfação em lecionar, o salário não condizente com a expectativa e as dificuldades oriundas de uma formação e reciclagem deficientes adicionada a total ausência de bibliografia e recursos de toda ordem faz com que este profissional, quase sempre, exerça os papéis que o caracterizem como um bom amigo e conselheiro em detrimento do conteúdo específico da disciplina com vistas a esperada capacitação profissional. Ao final de um ano letivo, parece existir a certa cumplicidade entre o aluno desinteressado e o professor desmotivado.

O regente da disciplina Educação Física Infantil apesar de ser considerado como corpo docente e tomar parte no planejamento da unidade escolar, sente-se conforme relato, isolado dos problemas pertinentes à escola.

Ministra sessões sujeito às intempéries e com freqüência e por ausência de tempo para estudar improvisa as aulas tanto teóricas como as de caráter prático. Utilizando sem a devida adaptação tão somente material específico do desporto coletivo, oferece um programa sem vínculo com o nível de aprofundamento que a habilitação como um todo se propõe.

Com relação aos estágios de observação e regência, quando existem, resumem-se ao preenchimento de papéis ou em aulas mal planejadas e mal dadas por parte dos educandos.

O processo de avaliação também não parece preocupar este docente uma vez que da maneira como é implementado parece não determinar a qualidade do curso por ele ministrado.

Apesar desta desalentadora realidade repleta de dificuldades que vão desde a insuficiente identificação da habilitação de forma geral aos problemas gerados por uma inadequada implementação, o professor regente ao analisar a capacitação profissional de seus alunos acredita que os mesmos possam ministrar com razoável eficiência as aulas de Educação Física quer na pré-escola quer nas classes de 1a. a 4a. série do 1o. grau.

\section{CONCLUSÃO E RECOMENDAÇÕES}

Ao que os fatos indicam o curso de Educação Física Infantil parece não estar correspondendo às reais necessidades da clientela nem tampouco vem sendo ministrado conforme sugestões dos especialistas da área. e alunos interessados.

Parece faltar quase tudo: orientação específica, instalações, material, professores competentes

Mediante esta exposição, sugere o pesquisador que sejam revistos os currículos e programas da habilitação em discussão no sentido de favorecer maior conhecimento e integração entre os componentes curriculares como recomenda Tyler (1986).

Se houver interesse no retorno deste componente, faz-se necessário um cuidadoso processo de implementação e intercâmbio entre os professores envolvidos.

Sugere o estudioso que exista por parte dos órgãos competentes, verdadeira intenção na melhoria da qualidade do ensino. Com igual intensidade solicita o autor deste trabalho que os diretores, supervisores e demais especialistas envolvidos em educação sistematizada, tenham formação acadêmica bem como acesso a informações ligadas ao processo ensino-aprendizagem da Educação Física Infantil.

\section{REFERÊNCIAS BIBLIOGRÁFICAS}

ARANTES, A.C. Educação nsica infantil nos cursos de habilitaçāo especifica de 20. grau para o magistério em São Paulo. São Paulo, 1990. 302p. Dissertação (Mestrado). - Escola de Educação Física, Universidade de São Paulo.

CAMPOS, A.N.Z.M. A escola normal paulista: acertos e desacertos. São Paulo, 1987. 123p. Dissertação (Mestrado) - Faculdade de Educação, Universidade de São Paulo. 
CANTARINO FILHO, M.R. A educação nisica no Estado Novo: história e doutrina. Brasília, 1982. 217p. Dissertação (Mestrado) - Universidade de Brasília.

CORPO e MOVIMENTO. Escola de Educação Física da Universidade de São Paulo. São Paulo, Associação dos Professores de Educação Física, v.1, n. 2, p.23, jun. 1984.

FUSARI, J.C. ; CORTESE, M.P. Formação de prefessores a nível de 20. grau. Cadernos de Pesquisa, São Paulo, n.68, p.70-80, 1989.

LELIS, I.A.O.M. A formação da professora primária: da denúncia ao anúncio. São Paulo, Cortez Autores Associados, 1989. 134p.

MEDALHA, J., coord. Educação fisica no currículo da escola de 1o. Grau. São Paulo, 1985. 75p. (trabalho não publicado)

PICONEZ, S.C.B. A habilitaçāo específica de 2o. grau para o magistério: expectativas e necessidades de sua clientela. São Paulo, 1988. 273p. Dissertaçāo (Mestrado) - Faculdade de Educação, Universidade de São Paulo.

PILETTI, N. Evolução do currículo do curso secundáriơ no Brasil. Revista Faculdade de Educação, São Paulo, v.13, n.2, p.27-72, jul/dez. 1987.

SÃo PAULO (Estado). Secretaria da Educaçāo. Coordenadoria de Estudos e Normas Pedagógicas. Habilitação específica de 20. grau para o magistério: proposta curricular de educação física. São Paulo, 1979. 27p.

SASAKI, R. Uma fábrica sem controle de qualidade. Nova Escola, v.3, n. 26, p.12-22, nov., 1988.

TYLER, R.W. Princípios básicos de currículo e ensino. 9.ed. Porto Alegre, Globo, 1986. 119p. 